Pacific Journal of Mathematics

FIXED-POINT THEOREMS IN LOCALLY CONVEX SPACES 


\title{
FIXED POINT THEOREMS IN LOCALLY CONVEX SPACES
}

\author{
T. L. HICKS
}

Let $C$ be a convex subset of a nuclear locally convex space that is also an $F$-space. Suppose $T: C \rightarrow C$ is nonexpansive and $\left\{v_{n}\right\}$ is given by the Mann iteration process. It is shown that if $\left\{v_{n}\right\}$ is bounded, $T$ has a fixed point. Also, a sequence $\left\{y_{n}\right\}$ can be constructed such that $y_{n} \rightarrow y$ weakly where $T y=y$. If $C$ is a linear subspace and $T$ is linear, then $\lim y_{n}=y$.

1. Introduction. With a few exceptions, the nonnormable locally convex spaces encountered in analysis are nuclear spaces. Precupanu [8]-[11] studied those locally convex spaces whose locally convex spaces whose generating family of seminorms satisfy the parallelogram law, and he called them H-locally convex spaces. Precupanu [9] observed that they include all nuclear spaces. This is immediate from Corollary 1, page 102 of [13]. Such a space that is also complete will be called a generalized Hilbert space. Theorem 2 generalizes a theorem of Reich [12] which generalizes a result of Dotson and Mann [2]. Reich's ingenious proof is modified to apply in this setting. Theorem 4 generalizes a result of Dotson [1]. His approach to the proof is used, but substantial changes are needed in the details.

Let $X$ be a $T_{2}$ locally convex space generated by a family $\left\{\rho_{\alpha}: \alpha \in \Delta\right\}$ of continuous seminorms. The function $\rho: X \rightarrow R^{4}$ is defined by

$$
(\rho(x))(\alpha)=\rho_{\alpha}(x), \quad x \in X, \quad \alpha \in \Delta .
$$

$\rho$ satisfies the axioms of norm. The topology $t_{\rho}$ generated by $\rho$ is the original topology where a $t_{\rho}$ neighborhood of $x$ is of the form

$$
\Omega(x, U)=\{y: \rho(x-y) \in U\}
$$

where $U$ is a neighborhood of zero in $R^{\Delta}$. Thus $\rho$ norms $X$ over $R^{4}$. A mapping $T$ from $X$ into $X$ is nonexpansive if $\rho(T x-T y) \leqq$ $\rho(x-y)$ for all $x, y \in X$; that is, $\rho_{\alpha}(T x-T y) \leqq \rho_{\alpha}(x-y)$ for all $x, y \in X$ and $\alpha \in \Delta$.

We look at the Mann iteration process. Let $C$ be a convex subset of $X$ and suppose $T$ maps $C$ into $C$. Suppose $A=\left[a_{n k}\right]$ is an infinite matrix satisfying:

$$
\begin{aligned}
& a_{n k} \geqq 0 \text { for all } n \text { and } k, \\
& a_{n k}=0 \text { for } k>n,
\end{aligned}
$$




$$
\begin{aligned}
\sum_{k=1}^{n} a_{n k}=1 & \text { for all } n, \text { and } \\
\lim _{n \rightarrow \infty} a_{n k}=0 & \text { for all } k .
\end{aligned}
$$

If $x_{1} \in C, \quad v_{1}=a_{11} x_{1}, \quad x_{2}=T v_{1}, \quad v_{2}=a_{21} x_{1}+a_{22} x_{2}, x_{3}=T v_{2}$ and, in general,

$$
v_{n}=\sum_{k=1}^{n} a_{n k} x_{k} \quad \text { and } \quad x_{n+1}=T v_{n}
$$

Thus for $n \geqq 2$,

$$
v_{n}=a_{n 1} x_{1}+\sum_{k=2}^{n} a_{n k} T v_{k-1}
$$

2. Results. In the remainder of this paper, $C$ will denote a convex subset of a $T_{2}$ locally convex space $(X, t)$ and $T: C \rightarrow C$ is nonexpansive.

TheOREM 1. If Tp $=p$ for some $p$ in $C$, the sequences $\left\{x_{n}\right\}$ and $\left\{v_{n}\right\}$ are bounded.

Proof. $t$ is given by the family $\left\{\rho_{\alpha}\right\}$ of seminorms and it suffices to show that for each $\alpha \in \Delta,\left\{\rho_{\alpha}\left(x_{n}\right)\right\}$ is bounded. The proof given in [2] carries over if you replace $\left\|x_{n}\right\|$ by $\rho_{\alpha}\left(x_{n}\right)$.

THEOREM 2. Suppose that every closed bounded convex subset of $C$ has the fixed point property for nonexpansive mappings. If for some $x_{1}$ in $C$ the sequence $\left\{v_{n}\right\}$ is bounded, then $T$ has a fixed point.

Proof. Let $y \in C$ and set

$$
R_{\alpha}=\lim _{n} \sup \rho_{\alpha}\left(y-v_{n}\right) \text {. }
$$

$R_{\alpha}$ is finite since $\left\{v_{n}\right\}$ is bounded. Let

$$
K_{\alpha}=\left\{z \in C: \lim _{n} \sup \rho_{\alpha}\left(z-v_{n}\right) \leqq R_{\alpha}\right\} .
$$

$K_{\alpha}$ is a closed in $t_{\rho_{\alpha}}$ and, therefore, closed in $t$ for every $\alpha \in \Delta$. Let

$$
\begin{aligned}
K & =\cap\left\{K_{\alpha}: \alpha \in \Delta\right\} \\
& =\left\{z \in C: \lim _{n} \sup \rho_{\alpha}\left(z-v_{n}\right) \leqq R_{\alpha} \text { for all } \alpha \in \Delta\right\} .
\end{aligned}
$$

$K \neq \phi$ since $y \in K . \quad K$ is closed bounded and convex. If $z \in K$ implies $T z \in K$, it follows that $T$ has a fixed point. Let $z \in K$ and $\alpha \in \Delta$. For each $\varepsilon>0$, there exists $N=N(\varepsilon, \alpha)$ such that $\rho_{\alpha}\left(z-v_{n}\right)<$ $R_{\alpha}+\varepsilon$ for all $n \geqq N$. For $n>N+1$, 


$$
\begin{aligned}
\rho_{\alpha}\left(T z-v_{n}\right)= & \rho_{\alpha}\left(\sum_{k=1}^{n} a_{n k} T z-a_{n 1} x_{1}-\sum_{k=2}^{n} a_{n k} T v_{k-1}\right) \\
\leqq & a_{n 1} \rho_{\alpha}\left(T z-x_{1}\right)+\sum_{k=2}^{n} a_{n k} \rho_{\alpha}\left(T z-T v_{k-1}\right) \\
\leqq & a_{n 1} \rho_{\alpha}\left(T z-x_{1}\right)+\sum_{k=2}^{n} a_{n \alpha} \rho_{k}\left(z-v_{k-1}\right) \\
\leqq & a_{n 1} \rho_{\alpha}\left(T z-x_{1}\right)+\sum_{k=2}^{N} a_{n k} \rho_{\alpha}\left(z-v_{k-1}\right) \\
& +\sum_{k=N+1}^{n} a_{n k}\left(R_{\alpha}+\varepsilon\right)=h(n)+R_{\alpha}+\varepsilon
\end{aligned}
$$

where $\lim _{n} h(n)=0$. Hence $T z \in K_{\alpha}$ for each $\alpha$ and, therefore, $T z \in K$.

THEOREM 3. Suppose $X$ is a nuclear locally convex space that is also an F-space. If for some $x_{1}$ in $C$ the sequence $\left\{v_{n}\right\}$ is bounded, then $T$ has a fixed point in $C$. In this case, $S_{\lambda}^{n} x_{1} \rightarrow y$ weakly where $T y=y$ and $S_{\lambda}=\lambda I+(1-\lambda) T, 0<\lambda<1$.

Proof. Let $K$ be as in Theorem 2. $K$ is a closed bounded convex subset of $C$ and, therefore, $K$ is weakly sequentially compact. Also, $T(K) \subseteq K$. By Theorem 2 of [4], $T$ has a fixed point in $K$. Applying Theorem 9 of [4] to $K$ gives the last part of the theorem.

REMARK. Theorem 3 is valid in any generalized Hilbert space in which closed, bounded, and convex subsets are weakly sequentially compact. One would like to have strong convergence of some sequence to a fixed point of $T$. The next theorem shows that if $T$ is linear and $C$ is a linear subspace, you have the desired result. One can not obtain strong convergence without some additional conditions; however, one should be able to replace the linearity of $T$ by some less restrictive condition.

THEOREM 4. Suppose $X$ is nuclear locally convex space that is also an $F$-space and $C$ is a linear subspace of $X$. If for some $x_{1}$ in $C$ the sequence $\left\{v_{n}\right\}$ is bounded and $T$ is linear, there exists $x_{0}$ $C$ such that $\lim _{n} S_{\lambda}^{n} x_{0}=y_{0}$ where $T y_{0}=y_{0}$.

Proof. Let $x_{0} \in K$ where $K$ is as in Theorem 3. $\left\{S_{\lambda}^{n}\left(x_{0}\right)\right\} \subseteq K$ and it has a subsequence that converges weakly to $y_{0}$ in $K$. We show that the sequence $\left\{S_{\lambda}^{n}\right\}_{n}$ of linear operators is a system of almost invariant integrals for the semigroup $\left\{T^{m}: m=0,1,2, \cdots\right\}$ and then apply the mean ergodic theorem of Eberlein [3] to obtain $\lim _{n} S_{\lambda}^{n} x_{0}=y_{0}$ with $T y_{0}=y_{0}$.

(1) $S_{\lambda}^{n}: C \rightarrow C$ is linear. 
(2) For each $n$ and each $x, S_{\lambda}^{n}(x)$ is in the convex hull of $x, T x, \cdots, T^{n} x$, since $T$ is linear gives

$$
S_{\lambda}^{n}=[\lambda I+(1-\lambda) T]^{n}=\sum_{j=0}^{n}\left(\begin{array}{c}
n \\
j
\end{array}\right) \lambda^{n-j}(1-x)^{j} T^{j} .
$$

(3) We show that $\left\{S_{\lambda}^{n}\right\}$ is an equicontinuous family. By a theorem of Banach [5, p. 169], it suffices to prove that $\left\{S_{\lambda}^{n}(x): n=\right.$ $0,1,2, \cdots\}$ is bounded for every $x$ in $K$. Thus it suffices to show that $\left\{\rho_{\alpha}\left(S_{\lambda}^{n}(x)\right): n=1,2, \cdots\right\}$ is bounded for every $\alpha \in \Delta$. This is true since

$$
\begin{aligned}
\rho_{\alpha}\left(S_{\lambda}^{n} x\right) & \leqq \sum_{j=0}^{n}\left(\begin{array}{c}
n \\
j
\end{array}\right) \lambda^{n-j}(1-\lambda)^{j} \rho_{\alpha}\left(T_{x}^{j}\right) \\
& \leqq \sum_{j=0}^{n}\left(\begin{array}{c}
n \\
j
\end{array}\right) \lambda^{n-j}(1-\lambda)^{j} \rho_{\alpha}(x) \\
& \leqq \rho_{\alpha}(x) .
\end{aligned}
$$

From the proof of Theorem 3, $T$ has a fixed point in $K$. From Theorem 6 of [4], $S_{\lambda}^{n+1} x-S_{\lambda}^{n} x \rightarrow 0$. Now

$$
\begin{aligned}
S_{\lambda}^{n+1} x-S_{\lambda}^{n} x & =S_{\lambda}\left(S_{\lambda}^{n} x\right)-S_{\lambda}^{n} x \\
& =\lambda S_{\lambda}^{n} x+(1-\lambda) T\left(S_{\lambda}^{n} x\right)-S_{\lambda}^{n} x \\
& =(1-\lambda)\left(T S_{\lambda}^{n} x-S_{\lambda}^{n} x\right) .
\end{aligned}
$$

Thus $T S_{\lambda}^{n} x-S_{\lambda}^{n} x \rightarrow 0$. Since $T$ is linear and continuous, $T^{2} S_{\lambda}^{n} x-$ $S_{\lambda}^{n} x=T\left(T S_{\lambda}^{n} x-S_{\lambda}^{n} x\right)-\left(T S_{\lambda}^{n} x-S_{\lambda}^{n} x\right) \rightarrow T(0)+0=0$. Using induction, we have

(4a) $T^{m} S_{\lambda}^{n} x-S_{\lambda}^{n} x \rightarrow 0$ as $n \rightarrow \infty$ for every $x$ in $C$ and all $m=$ $0,1,2, \cdots$.

Since $S_{\lambda}^{n}$ is a polynomial in $T, T^{m} S_{\lambda}^{n}=S_{\lambda}^{n} T^{m}$ and, using (4a), we have

(4b) $S_{\lambda}^{n} T^{m} x-S_{\lambda}^{n} x \rightarrow 0$ as $n \rightarrow \infty$ for every $x$ in $C$ and all $m=$ $0,1,2, \cdots$. Now, we apply the mean ergodic theorem to obtain the desired result.

REMARK. $\left\{S_{\lambda}^{n} x_{1}\right\}$ is a special sequence $\left\{v_{n}\right\}$ given by the Mann iteration process. Just let $a_{n 1}=\lambda^{n-1}, a_{n j}=\lambda^{n-j}(1-\lambda)$ for $j=$ $2,3, \cdots, n$, and $a_{n j}=0$ for $j>n, n=1,2,3, \cdots$.

\section{REFERENCES}

1. W. G. Dotson, Jr., On the Mann iteration process, Trans. Amer. Math. Soc., 149 (1970), 65-73.

2. W. G. Dotson, Jr. and W. R. Mann, A generalized corollary of the Browder-Kirk fixed point theorem, Pacific J. Math., 26 (1968), 455-459. 
3. W. F. Eberlein, Abstract ergodic theorems and weak almost periodic functions, Trans. Amer. Math. Soc., 67 (1949), 217-240.

4. T. L. Hicks and Ed. W. Huffman, Fixed point theorems in generalized Hilbert spaces, J. Math. Anal. and Appl., 64 (1978), 562-568.

5. G. Kothe, Topological Vector Spaces I, Springer Verlag, New York, (1969).

6. W. Robert Mann, Mean value methods in iteration, Proc. Amer. Math. Soc., 4 (1953), 506-510.

7. A. Pietsch, Nuclear Locally Convex Spaces, Springer Verlag, New York, (1972).

8. T. Precupanu, Sur les produits scalaires dans des espaces vectoriels topologiques, Rev. Roum. Math. Pures et Appl., (1968), 85-90.

9. _ Espaces lineaires a seminormes hilbertiennes, An. st. Univ. Iasi, servia mat., 15 (1969), 83-93.

10. - Bases orthogonales dans des espaces lineaires a semi-normes hilbertiennes, Rev. Roum. Math. Pures et Appl., 15 (1970), 1035-1038.

11. — Sur l'espace dual d'un espace lineaires a semi-normes hilbertiennes. (Romanian Summary), An. Sti. Univ., “Al. I. Cuza” Iasi sect. I a mat. (N.S.), 19 (1973), 73-78.

12. Simeon Reich, Fixed point iterations of nonexpansive mappings, Pacific J. Math., 60 (1975), 195-198.

13. H. H. Schaefer, Topological Vector Spaces, The Macmillian Company, New York, (1966.)

Received March 7, 1977.

UNIVERSITY OF MisSOURI-RoLLA

ROLLA, MO 65401 



\section{PACIFIC JOURNAL OF MATHEMATICS}

EDITORS

RICHARD ARENS (Managing Editor)

University of California

Los Angeles, California 90024

C. W. Curtis

University of Oregon

Eugene, OR 97403

C. C. MOORE

University of California

Berkeley, CA 94720
J. DUGUNDJI

Department of Mathematics University of Southern Californı Los Angeles, California 90007

R. Finn and J. Milgram Stanford University Stanford, California 94305

\section{ASSOCIATE EDITORS}

E. F. BECKENBACH

B. H. NEUMANN

F. WOLF

K. YoSHIDA

\section{SUPPORTING INSTITUTIONS}

UNIVERSITY OF BRITISH COLUMBIA
CALIFORNIA INSTITUTE OF TECHNOLOGY
UNIVERSITY OF CALIFORNIA
MONTANA STATE UNIVERSITY
UNIVERSITY OF NEVADA, RENO
NEW MEXICO STATE UNIVERSITY
OREGON STATE UNIVERSITY
UNIVERSITY OF OREGON

UNIVERSITY OF SOUTHERNEALIFORNIA STANFORD UNIVERSITY UNIVERSITY OF HAWAII UNIVERSITY OF TOKYO UNIVERSITY OF UTAH WASHINGTON STATE UNIVERSITY UNIVERSITY OF WASHINGTON 


\section{Pacific Journal of Mathematics \\ Vol. 79 , No. 1 \\ May, 1978}

Teófilo Abuabara, A remark on infinitely nuclearly differentiable

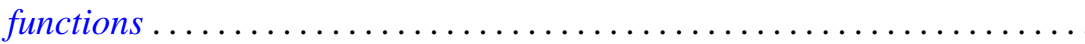

David Fenimore Anderson, Projective modules over subrings of $k[X, Y]$

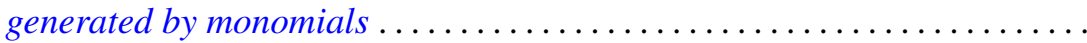

Joseph Barback and Thomas Graham McLaughlin, On the intersection of

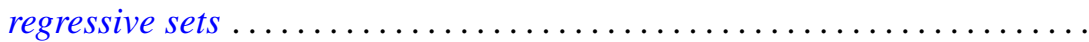

Murray Bell, John Norman Ginsburg and R. Grant Woods, Cardinal inequalities for topological spaces involving the weak Lindelof

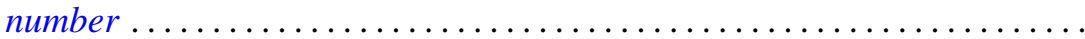

Laurence Richard Boxer, The space of ANRs of a closed surface ............

Zvonko Cerin, Homotopy properties of locally compact spaces at

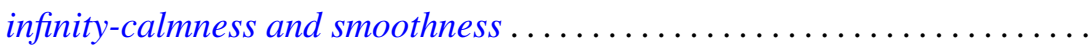

Isidor Fleischer and Ivo G. Rosenberg, The Galois connection between partial functions and relations..................................

John R. Giles, David Allan Gregory and Brailey Sims, Geometrical implications of upper semi-continuity of the duality mapping on a Banach

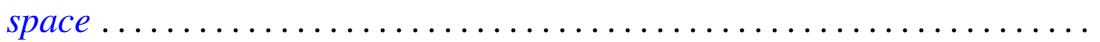

Troy Lee Hicks, Fixed-point theorems in locally convex spaces ............ Hugo Junghenn, Almost periodic functions on semidirect products of transformation semigroups ........................

Victor Kaftal, On the theory of compact operators in von Neumann algebras. II . . . .

Haynes Miller, A spectral sequence for the homology of an infinite

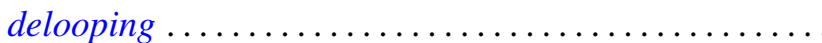

Sanford S. Miller, Petru T. Mocanu and Maxwell O. Reade, Starlike integral operators...

Stanley Stephen Page, Regular FPF rings ...............

Ghan Shyam Pandey, Multipliers for C, 1 summability of Fourier series ...

Shigeo Segawa, Bounded analytic functions on unbounded covering surfaces...

Steven Eugene Shreve, Probability measures and the C-sets of

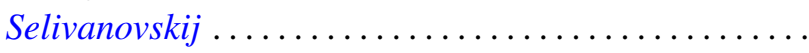

Tor Skjelbred, Combinatorial geometry and actions of compact Lie groups....

Alan Sloan, A note on exponentials of distributions.

Colin Eric Sutherland, Type analysis of the regular representation of a nonunimodular group.

Mark Phillip Thomas, Algebra homomorphisms and the functional

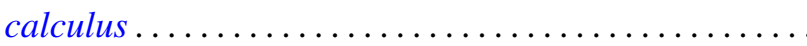

Sergio Eduardo Zarantonello, A representation of $H^{p}$-functions with

$0<p<\infty$. 